\title{
Optimization of Scanning Scheme for Low-height Vegetation Survey Based on Terrestrial Laser Scanning - A Case Study on the Restored Sand Land, Southern Qinghai-Tibetan Plateau
}

Jiarong Tian

Nanjing Forestry University https://orcid.org/0000-0002-9402-5668

Haidong Li

Nanjing Institute of Environmental Sciences

Weibo Ma

Nanjing Institute of Environmental Sciences

Chengrui Liao

Nanjing Forestry University

Yannan Xu ( $\square$ nfuxyn@njfu.edu.cn )

Nanjing Forestry University

\section{Research}

Keywords: terrestrial laser scanning, scanning mode, scanning spot, low-height vegetation, terrain fluctuation

Posted Date: January 5th, 2021

DOI: https://doi.org/10.21203/rs.3.rs-138858/v1

License: (c) (i) This work is licensed under a Creative Commons Attribution 4.0 International License. Read Full License 


\section{Abstract}

Background: In recent decades, vegetation surveys based on terrestrial laser scanning (TLS) have developed rapidly, especially on the forest inventory, but few studies have been conducted to the lowheight vegetation. Because of the high investigation cost and subjectivity, it is impending to provide a scientific scanning scheme based on the TLS for the low-height vegetation survey (e.g. shrub, grassland, and meadow) in eco-fragile region (e.g. Qinghai-Tibetan Plateau).

Method: In this study, we extracted the vegetation parameter i.e., number, height $(\mathrm{H})$, and crown width (CW) of the two sample plots to evaluate the integrity of the data collected by TLS, on the restored sand land in southern Qinghai-Tibetan Plateau. We assessed the difference between the scanning mode of single-scan (SS) and multiple-scan (MS), and evaluated the influence of terrain fluctuation (windward slope, leeward slope, and the peak of slope) on the determination of scanning spots.

Results: The results showed that: (1) the accuracy of vegetation parameter extracted by the mode of SS was mainly affected by the occlusion and the distance from central scanning spot, the RMSE of vegetation parameters is the smallest $\left(\mathrm{RMSE}_{\mathrm{H}}=0.186 \mathrm{~m} ; \mathrm{RMSE}_{\mathrm{CW}}=0.208 \mathrm{~m}\right.$ ) within $20 \mathrm{~m}$ from the central scanning spot. (2) For the MS mode, in addition to the central scanning spot, the scanning spot located at the peak of the slope is the most important, which was the connection of combining the data of windward slope and leeward slope.

Conclusion: To sum up, the scientific layout of scanning spot is the key to collecting data by TLS efficiently, and topography is the main factor affecting the layout of scanning spot. Since occlusion effect cannot be avoided, it can only be compensated by setting up more scanning points. Secondly, the accuracy of different sensors will has influence on the distance between adjacent scanning spots.

\section{Introduction}

Vegetation types such as shrub, grassland, and meadow have the characteristics of low-height and distributed widely (Li et al., 2019), and play an important role in the global carbon cycle (Scurlock and Hall. 1998), prevention of land degradation (Liao et al., 2019), and biodiversity conservation (Dong et al., 2020). It was reported that the grassland has been seriously degraded since the 1980s, and accompanied with shrub encroachment (Eldridge et al., 2011), causing losses in grassland biodiversity, water retention capability, and soil nutrients (Andrade et al., 2015; Chen et al., 2017). Therefore, vegetation restoration of degraded grassland is essential to maintain the functions and services of grassland ecosystems.

From 2008 to 2017, we established a set of experimental plots for vegetation restoration of degraded grasslands, and selected suitable vegetation restoration species by comparing vegetation parameters (Li et al., 2019). Traditionally, the vegetation parameters for the low-height vegetation were estimated in combination with field surveys and optical remote sensing data (Psomas et al., 2011), the Light Detecting and Ranging (LiDAR) technology, which can provide three-dimensional (3D) information, has gradually replaced traditional investigation method for vegetation survey. Terrestrial laser scanning (TLS) can 
provide the vertical structure information of vegetation with millimeter-level accuracy (Liang et al., 2018), which has unique advantages for collecting vegetation information on sample scale (Liang et al., 2012; Liang and Hyyppä. 2013), such as diameter at breast height (Kankare et al., 2015), height (Tian et al., 2019), and biomass estimation (Calders et al., 2015). However, LiDAR as a tool for vegetation investigation were, so far, primarily used for forest inventories (Liang et al., 2016), the application in lowheight eco-system was rarely investigated (Wachendorf et al., 2017; Li et al., 2019;).

TLS scanning are divided into the mode of single-scan (SS) and multiple-scan (MS) (Liang et al., 2016), most of researches on scanning method are to compare the difference between these two modes in the forest inventories (Pueschel et al., 2013; Saarinen et al., 2017). For the low-height vegetation, Li et al (2019) utilized the TLS date obtained by registering 18 scanning spots to assess the effects of topography on the revegetation. Xu et al (2020) estimated the grassland aboveground biomass from the TLS data obtained by 5 scanning spots. Both studies adopted TLS data registered by the mode of MS to obtain more complete information of the sample plot. Damian et al (2019) indicated that in the process of estimating grass biomass by TLS, two scans from opposite directions slightly increased the spatial information compared to one scan only. Therefore, it is important to arrange the location of the scanning spots reasonably for the date acquisition.

As a matter of fact, we should reduce the risk and cost of the vegetation investigation in some areas with harsh environmental conditions (e.g. the plateau region like Qinghai-Tibet Plateau), and improve the data acquisition in terms of efficiency, robustness, and precision. Trochta et al. (2013) mentioned that occlusion is one of the key factors that limited the potential of TLS data acquisition. Occlusion is caused by objects shadowing each other, so that some part of the objects of interest are not visible to the scanning spots with only one side. The effect of occlusion is usually mitigated by combining TLS scans from different locations (Hilker et al., 2012). But few studies provided a standard for the location determination of scanning spots, and explored the factors affecting the completeness of data collection. Therefore, we mainly discussed the difference of the scan mode in the data acquisition of low-height vegetation, and explored the influence of terrain features (i.e. the slope and the fluctuation of terrain) for setting scanning spots. We selected some vegetation parameters for comparison, including the number $(\mathrm{N})$, height $(\mathrm{H})$, and crown width $(\mathrm{CW})$, because these parameters can directly reflect the growth status of the vegetation (Li et al., 2016). We provided two hypotheses in this study: (1) for the low-height shrub, the mode of SS could be competent for information collection, but the occlusions from the vegetation and the distance from the central scanning spot were the main limiting factors (2) the fluctuation of terrain has a great influence on setting scanning spots. In addition, we will provide a reasonable suggestion for setting the scanning spots and optimizing the scanning scheme according to the different data requirements.

\section{Materials And Methods \\ 2.1 Study Area}


There are two sample plots in this study, the plot \#1 was located on the north of the highway from Zedang to Sangye in Shannan city $\left(91.324^{\circ} \mathrm{E}, 29.181^{\circ} \mathrm{N}\right)$, and the altitude is about $3560 \mathrm{~m}$ above sea level. The plot \#2 were located on the third fluvial terrace of the Yarlung Zangbo River in Gongga County, Tibetan Autonomous Region of China ( $90.889^{\circ} \mathrm{E}$ and $29.337^{\circ} \mathrm{N}$ near the Lhasa Airport), with altitudes ranging from $3560 \mathrm{~m}$ to $3730 \mathrm{~m}$ above sea level. These areas belong to the semi-arid plateau temperate monsoon climate zone with the annual precipitation of approximately $300-450 \mathrm{~mm}$ and the annual daily mean temperature between 6.3 and $8.7^{\circ} \mathrm{C}$.

\subsection{Data Collection}

We used the RIEGL VZ-400i scanning system to conduct TLS scanning of sample plot \# 1 on June 30th, 2017, and the scanning of sample plot \#2 was carried out on July 1st, 2017. The VZ-400i TLS has a field view of $360^{\circ}$ (horizontal) $\times 100^{\circ}$ (vertical), an accuracy of $\pm 5 \mathrm{~mm}$ per $100 \mathrm{~m}$. This TLS system acquires $3 \mathrm{D}$ point cloud at a speed up to 500,000 points per second, and every scanning spot spent about 20 seconds with a high-speed model.

Table 1

the information of three sample plots

\begin{tabular}{|lllll|}
\hline Sample plot ID & Size $(\mathrm{m})$ & Vegetation Coverage (\%) & Slope (\%) & Terrain \\
\hline 1 & $100 * 100$ & 60 & 3.8 & flat \\
2 & $50 * 50$ & 35 & 56.2 & fluctuant \\
\hline
\end{tabular}

When collecting TLS data for the sample plot (square), one central scanning spot was determined firstly in the center of the plot, and four peripheral scanning spots were located near the four corners of the sample plot (Fig. 1c). In addition, we recorded the terrain features (including the slope and the fluctuation of terrain) and the vegetation coverage of the sample plot (Table 1).

\subsection{Data Processing and Analysis}

\subsubsection{TLS pre-processing}

The point cloud data collected at each scanning spot was freely combined and registered according to the experimental requirements, and we uniformly named the data set to facilitate understanding and writing. The $\mathrm{DS}_{1-(r)}$ and $D S_{2-(r)}$ represent the reference data set collected by 5 scanning spots of the sample plot \#1 and \#2, the $D S_{1-(n)}$ and $D S_{2-(n)}$ represent the experimental data set collected by the $n^{\prime}$ th scanning spot, and the $\mathrm{DS}_{1-(\mathrm{n}-)}$ and $\mathrm{DS}_{2-(\mathrm{n}-)}$ represent the experimental data set collected by all the scanning spots except the n'th scanning spot (the specific number of the scanning spots could be found in Fig. 1c). In previous research (Tian et al., 2020), we have evaluated the extraction accuracy of the $\mathrm{H}$ and CW between the reference data set ( 5 scanning spots) and the field-measured data $\left(R^{2}=0.944\right.$ and 0.970 , respectively), which verified the integrity of reference data set based on TLS. 
The registration was based on the close-range point clouds (Besel and McKay., 1992) and registration poles using the RiSCAN Pro software (http://www.riegl.com). All the registered data were preprocessed in the LiDAR360 software (https://www.lidar360.com), and the procedure including the denoising, filtering, and normalization. Firstly, the statistical outlier removal filter was utilized in the step of denoising. Secondly, the ground point was separated based on the progressive triangulated irregular network densification filter (Zhao et al., 2016), and the digital elevation model (DEM) at a resolution of $0.02 \mathrm{~m}$ was obtained by the Kriging interpolation (Guo et al., 2010). Finally, the normalized point cloud data was obtained by subtracting the corresponding DEM value from the height value of point.

\subsubsection{Vegetation parameter extraction between SS and MS}

Due to the large number of individual vegetation in sample plot $\# 1$, we set up 12 small quadrats (10 $\mathrm{m} \times$ $10 \mathrm{~m}$ ) according to different distances from the central scanning spot (Fig. 2), and the distance was $20 \mathrm{~m}$ (quadrat \#9-12), $35 \mathrm{~m}$ (quadrat \#5-8), and $50 \mathrm{~m}$ (quadrat \#1-4), respectively. We extracted the $\mathrm{N}, \mathrm{H}$, and $\mathrm{CW}$ of the vegetation in the 12 quadrats from the $\mathrm{DS}_{1-(r)}$ and $\mathrm{DS}_{1-(5)}$. Then, the difference between MS (5 scanning spots) and SS (central scanning spot) could be compared from the vegetation parameters of 12 quadrats, and the influence of distance between the quadrat and the central scanning spot for data collection.

The difference of the slope between the sample plot \#1 and \#2 is obvious, $3.8 \%$ and $56.2 \%$, respectively. The terrain has a fluctuation in the sample plot 2, while the sample plot \#1 is flat. We extracted the same vegetation parameters of all vegetation from the $\mathrm{DS}_{2-(r)}$ and $\mathrm{DS}_{2-(5)}$, for testing the applicability of SS (central scanning spot) in steep slope area.

\subsubsection{The influence of terrain features}

In this part, we obtained the terrain features at the location of the n'th scanning spot through DEM data of the sample plot 2\#. The fluctuation of the dunes is mostly caused by wind erosion (Liao et al., 2020), and the highest location between the windward slope and the leeward slope is known as the slope peak (Fig. 3). In order to analyze the importance of each scanning spot for data collection by TLS, we take any scanning spot in sample plot \#2 as an impact factor, and compared the vegetation parameter extracted from the $\mathrm{DS}_{2-(\mathrm{r})}$ and $\mathrm{DS}_{2-(\mathrm{n}-)}$.

\subsubsection{The error analysis}

The error analysis of the vegetation parameters extracted by the experimental Data Set and the reference Data Set $\left(\mathrm{DS}_{1-(\mathrm{r})}\right.$ and $\left.\mathrm{DS}_{2-(\mathrm{r})}\right)$ was determined based on the root mean squared error (RMSE), the equations as follow:

$$
R M S E=\sqrt{\frac{\sum_{i=1}^{n}\left(V P_{r e f}-V P_{e}\right)^{2}}{n}}
$$


where $V P$ represent the vegetation parameter (including the $\mathrm{H}$ and $\mathrm{CW}$ ), $V P_{\text {ref }}$ is the vegetation parameter extracted by the $D S_{1-(r)}$ and $D S_{2-(r)}, V P_{e}$ is the vegetation parameter extracted by the experimental Data Set, and the experimental Data Set include the data combination of different scanning spots.

\section{Results}

\subsection{Vegetation parameter extraction between SS and MS}

As shown from Table 2, for the reference vegetation parameter $\left(V P_{r e f}\right)$ from the $\mathrm{DS}_{1-(\mathrm{r})}$ and $\mathrm{DS} \mathrm{S}_{2-(\mathrm{r})}$, the $\mathrm{H}-$ mean of the 12 quadrats ranges from $0.95 \mathrm{~m}$ to $1.05 \mathrm{~m}$, and the $\mathrm{CW}$-mean varies from $1.23 \mathrm{~m}$ to $1.38 \mathrm{~m}$. The vegetation of sample plot 2 is higher and bigger than the sample plot \#1, the $\mathrm{H}$-mean and $\mathrm{CW}$-mean is $2.86 \mathrm{~m}$ and $4.24 \mathrm{~m}$, respectively.

Table 2

the vegetation parameter extracted by $\mathrm{DS}_{1-(r)}$ and $\mathrm{DS}_{2-(\mathrm{r})}$

\begin{tabular}{|llllllll|}
\hline Sample plot ID & & \multicolumn{3}{c}{ Height $(\mathrm{m})$} & \multicolumn{4}{c|}{ Crown Width $(\mathrm{m})$} \\
\cline { 3 - 8 } & & $\max$ & $\min$ & mean & max & min & mean \\
\hline Sample plot \#1 & Quadrats \#1-4 & 2.21 & 0.50 & 1.03 & 2.35 & 0.27 & 1.23 \\
& Quadrats \#5-8 & 3.12 & 0.55 & 1.05 & 3.02 & 0.59 & 1.38 \\
& Quadrats \#9-12 & 1.83 & 0.59 & 0.95 & 2.44 & 0.56 & 1.23 \\
\hline Sample plot \#2 & & 5.56 & 0.96 & 2.86 & 10.40 & 1.32 & 4.24 \\
\hline
\end{tabular}

We compared the results of $\mathrm{N}, \mathrm{H}$-mean, and CW-mean extracted from the $\mathrm{DS}_{1-(5)}, \mathrm{DS}_{2-(5)}, \mathrm{DS}_{1-(\mathrm{r})}$ and $\mathrm{DS}_{2-(\mathrm{r})}$ (Table 3). In the sample plot \#1, the proportion of extracted vegetation number ( $\mathrm{Ns} / \mathrm{Nr}$ ) followed the order of Quadrat \#9-12 (97.9\%) > \#5-8 (94.8\%) > \#1-4 (40.6\%), and the RMSE of the H-mean and the CW-mean followed the same order, the minimum value all appears in the Quadrat \#9-12, is $0.186 \mathrm{~m}$ and $0.208 \mathrm{~m}$, respectively. There are total 40 shrubs in the sample plot \#2, and 95 percent of the vegetation was extracted, the RMSE of the H-mean and CW-mean are $0.4 \mathrm{~m}$ and $0.854 \mathrm{~m}$, respectively. 
Table 3

the error analysis of vegetation parameter extracted from $\mathrm{DS}_{1-(5)}, \mathrm{DS}_{2-(5)}, \mathrm{DS}_{1-(\mathrm{r})}$ and $\mathrm{DS}_{2-(\mathrm{r})}$

\begin{tabular}{|c|c|c|c|c|c|c|}
\hline \multirow[t]{2}{*}{ Sample plot ID } & & \multicolumn{3}{|c|}{ Number $(\mathrm{N})$} & \multirow{2}{*}{$\begin{array}{l}\text { H-mean (m) } \\
\text { RMSE }\end{array}$} & \multirow{2}{*}{$\begin{array}{l}\text { CW-mean (m) } \\
\text { RMSE }\end{array}$} \\
\hline & & Ns & $\mathrm{Nr}$ & $\mathrm{Ns} / \mathrm{Nr}$ & & \\
\hline \multirow[t]{3}{*}{ Sample plot \#1 } & Quadrats \#1-4 & 26 & 64 & 0.406 & 0.621 & 0.470 \\
\hline & Quadrats \#5-8 & 55 & 58 & 0.948 & 0.409 & 0.313 \\
\hline & Quadrats \#9-12 & 93 & 95 & 0.979 & 0.186 & 0.208 \\
\hline Sample plot \#2 & & 38 & 40 & 0.950 & 0.400 & 0.854 \\
\hline
\end{tabular}

\subsection{Terrain feature of the scanning spots}

We extracted the terrain type at the location of 5 scanning spots of the sample plot \#2 according to the DEM data (Fig. 4a), the terrain feature of scanning spot \#1, \#2, and \#5 is windward slope, scanning spot \#3 is leeward slope, and scanning spot \#4 is slope peak. The number of vegetation on the windward slope and slope peak was significantly more than that on the leeward slope (Fig. 4b).

Table 4

\begin{tabular}{|c|c|c|}
\hline \multirow[t]{2}{*}{ Experimental Data Set } & H-mean (m) & CW-mean (m) \\
\hline & RMSE & RMSE \\
\hline $\mathrm{DS}_{2-(1-)}$ & 0.009 & 0.064 \\
\hline $\mathrm{DS}_{2-(2-)}$ & 0.087 & 0.083 \\
\hline $\mathrm{DS}_{2-(3-)}$ & 0.127 & 0.148 \\
\hline $\mathrm{DS}_{2-(4-)}$ & 0.152 & 0.140 \\
\hline $\mathrm{DS}_{2-(5-)}$ & 0.026 & 0.191 \\
\hline
\end{tabular}

We compared the vegetation parameters extracted by the $\mathrm{DS}_{2-(r)}$ and $\mathrm{DS}_{2-(\mathrm{n}-)}($ Table. 4), all the experimental data set $\left(\mathrm{DS}_{2-(\mathrm{n}-)}\right)$ could integrally identify the number of vegetation in sample plot \#2. The 


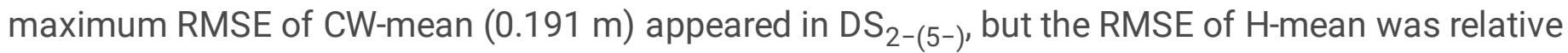
small $(0.026 \mathrm{~m})$, which indicated that the data set combined 4 peripheral scanning spots had a lack of the vegetation information at the center of the sample plot \#2, especially the $\mathrm{CW}$. For the other Date Sets, the RMSE of H-mean followed the order of $\mathrm{DS}_{2-(1-)}(0.009 \mathrm{~m})<\mathrm{DS}_{2-(2-)}(0.087 \mathrm{~m})<\mathrm{DS}_{2-(3-)}(0.127 \mathrm{~m})<$ $\mathrm{DS}_{2-(4-)}(0.152 \mathrm{~m})$, and the RMSE of CW-mean followed the order of $\mathrm{DS}_{2-(1-)}(0.064 \mathrm{~m})<$ $\mathrm{DS}_{2-(2-)}(0.083 \mathrm{~m})<\mathrm{DS}_{2-(4-)}(0.140 \mathrm{~m})<\mathrm{DS}_{2-(3-)}(0.148 \mathrm{~m})$. So, except the central scanning spot \#5, the importance of 4 peripheral scanning spots for data collection followed the order of scanning spot \#4 >\#3 $>$ \#2 > \#1.

\section{Discussion}

\subsection{Evaluation of the Single-Scan (SS)}

Comparing the SS $\left(\mathrm{DS}_{1-(5)}\right)$ with the MS $\left(\mathrm{DS}_{1-(\mathrm{r})}\right)$ in the sample plot $\# 1$, we found that the vegetation parameter extracted from the quadrats \#9-12 has the minimum error, which proved that the completeness of data collection based on SS would be affected by the distance from the central scanning spot. So the closer the distance, the more complete the data collection, but the scan blindness (a circular region with a radius of about $2 \mathrm{~m}$ ) should be considered for setting quadrats (Tian et al., 2019). The H-mean and CW-mean of vegetation in the quadrats \#9-12 are $0.95 \mathrm{~m}$ (RMSE $=0.186 \mathrm{~m}$ ) and $1.23 \mathrm{~m}$ (RMSE $=0.208 \mathrm{~m}$ ), Therefore, the vegetation parameter extracted based on the data within $20 \mathrm{~m}$ from the central scanning spot collected by SS could provide about $80 \%$ accuracy. The sampled plot size for shrubland is usually from $5 \mathrm{~m} \times 5 \mathrm{~m}$ to $20 \mathrm{~m} \times 20 \mathrm{~m}$ (Ministry of Environmental Protection of China, 2014) (Li et al., 2019), so the data within $20 \mathrm{~m}$ from the central scanning spot could meet the size requirement. In addition, we found the major factor for the error of the vegetation parameter extracted from the quadrats \#9-12 is the occlusions from a few shrubs (Fig. 5a \& 5c). Wan et al. (2019) extracted the tree stem curve from single-scan TLS data, also found that the occlusions from tree stems were the main factor of the low detection rate of stem. Therefore, the occlusions decreased the accuracy of the vegetation parameter extracted by the mode of SS.

In the sample plot \#2, the H-mean and CW-mean of vegetation are $2.86 \mathrm{~m}$ (RMSE $=0.4 \mathrm{~m}$ ) and $4.24 \mathrm{~m}$ $($ RMSE $=0.854 \mathrm{~m})$, which proved that the vegetation parameter of the steep slope area extracted by SS could also provide about $80 \%$ accuracy, and the occlusion also was the major factor for the error. In addition, we found that the occlusions come not only from other vegetation (mainly affect the extraction of $\mathrm{H}$, Fig. 5b), but also from some vegetation itself (mainly affect the extraction of CW, Fig. 5d), because only one side of the vegetation information was collected by the mode of SS (Damian et al., 2019).

\subsection{Evaluation of the Terrain features}

For the sample plot \#2 with steep slope and a fluctuation, we believed that each scanning spot contributes to the data acquisition firstly (Table.4). The central scanning spot \#5 have a strong ability of collecting the overall vegetation information in the sample plot \#2 (Table.3), but some scanning spots 
(like the scanning spot \#1) have a small contribution, which could be replaced by other scanning spots (like the scanning spot \#2), because the location of scanning spot \#1 and \#2 belongs to windward slope, and there are more vegetation around the scanning spot \#2 (Fig. 4b). Scanning spot \#4 was located at the peak of the slope (Fig. 4a) and had an excellent scanning vision, which was the connection scanning spot of combining the data of windward slope and leeward slope, and compensated for the lack of information due to the fluctuation of terrain. From this result, we can infer that if the central scanning spot \#5 moves down to the position of the slope peak (Fig. 4a), it can make the data quality collected by SS mode better, because of the supplement to the vegetation information on the leeward slope. Scanning spot \#3 mainly provided the vegetation information of the leeward slope, because of the far distance from scanning spot \#4 and the occlusions caused by the tall vegetation on the leeward slope, the complete vegetation information of the leeward slope cannot be obtained by the single scanning spot \#4, so the scanning spot \#3 is very important for the data collection of sample plot \#2.

\subsection{Suggestions for setting the scanning spots of TLS}

For the forest inventories, Abegg et al. (2017) have explained the influence of the scanner placement on the quality of the scans in terms of completeness, and found that stand describing parameters (e.g. diameter distribution, stem number and dominant diameter), distance to the scanner, and object size all have an impact on data acquisition quality. Too many factors will increase the difficulty of data collection and test the data acquisition experience of the collector. But for the low-height vegetation, we just need to consider the terrain factor and the occlusion in the scanning direction. Because most of the occlusion problems have been addressed by the height difference between the scanner and the vegetation, if the scanner is at the same height level as the vegetation, or below the height level of the vegetation, it will face the same problems encountered by forest inventories.

In addition, we summarized some key points of setting scanning spots according to the different requirements of data collection and the different situation of the sample plot. (1) The scanning mode of SS is suitable for the rapid acquisition of vegetation information in the sample plot, which has a low requirement for the extraction accuracy of vegetation parameters. Besides, the location of central scanning spot should consider the fluctuation of terrain rather than the slope, and it is best to choose the slope peak near the center of sample plot, which could reduce the occlusion of the terrain. (2) The scanning mode of MS could be used when we need the vegetation parameters with high precision. Firstly, we need survey the situation of terrain and vegetation before setting up the scanning spots in the sample plot, and determine the central scanning spot based on the SS method preferentially. Secondly, the determination of peripheral scanning spots should consider the occlusion caused by the terrain and vegetation in the scanning direction. Therefore, the peripheral scanning spots need to be located in the areas with different terrain features (including windward slope, leeward slope, and slope peak). Finally, if some large vegetation was found in one scanning direction of the central scanning spot, a peripheral scanning spot need to be set in the opposite direction. (3) Taking the equipment used in this study as an example (RIEGL VZ-400i), we need pay attention to the size of the sample plot or the distance between the scanning spots. The size of the sample plot (square) should not exceed $50 \mathrm{~m}$ for the scanning mode 
of SS (Table.3), or the information on the edge of the sample plot is not reliable. In addition, the distance between the adjacent scanning spots should also not exceed $50 \mathrm{~m}$ for the scanning mode of MS, to ensure the repeatability and complementarity of the point cloud. Finally, it should be noted that the reasonable distance between scanning spots varies greatly depending on the specific parameters of the scanner, it is necessary to test the reasonable distance between scanning spots before the formal data acquisition.

\section{Conclusion}

In this paper, we evaluated the applicability of the SS mode by comparing the vegetation parameters (number, height, and crown width) extracted with the scanning mode of MS, and analyzed the influence of terrain features for setting scanning spots. We confirmed that the SS mode has strong applicability in the field-survey of low-height vegetation. However, the accuracy will be affected by the size of sample plot and the occlusion caused by the terrain and vegetation. In addition, we have provided a relatively complete method to set up the scanning spots for SS and MS modes, and we believed that the quickly acquirement of the terrain information is a prerequisite for reasonably determining the location of the scanning spots. Therefore, the adoption of unmanned aerial vehicle for terrain data collection before the TLS scanning can greatly reduce the cost and improve the collecting efficiency.

\section{Declarations}

\section{Acknowledgements}

We would like to thank Guopin Lv and Weicheng Hua for LiDAR data collection and preprocessing.

\section{Funding}

The research was supported by A Basic Special Business Fund for R\&D for the Central Level Scientific Research Institutes, Nanjing Institute of Environmental Sciences, Ministry of Ecology and Environment (GYZX190101 and GYZX170201), and Postgraduate Research \& Practice Innovation Program of Jiangsu Province (KYCX19_1096).

\section{Author Contributions}

Haidong Li conceived and designed the research, Yannan Xu helped to improve the hypothesis, Jiarong Tian wrote the paper, Chengrui Liao, Weibo Ma, Jiarong Tian carried out the field work and the analysis, Yannan Xu contributed to the discussion, and paper revision.

\section{Availability of data and materials}


The datasets used and/or analyzed during the current study are available from the corresponding author on reasonable request.

\section{Ethics approval and consent to participate}

Not applicable.

\section{Consent for publication}

Not applicable.

\section{Competing interests}

The authors declare no competing interests.

\section{References}

1. Abegg, M., Kukenbrink, D., Zell, J., Schaepman, M.E., Morsdorf, F., 2017. Terrestrial Laser Scanning for Forest Inventories Tree Diameter Distribution and Scanner Location Impact on Occlusion. Forests, 8(6),184. DOI: 10.3390/f8060184

2. Andrade, B.O., Koch, C., Boldrini, I.I., Vélez-Martin, E., Hasenack, H., Hermann, J., Kollmann, J., Pillar, V.D., Overbeck, G.E., 2015. Grassland degradation and restoration: a conceptual framework of stages and thresholds illustrated by southern Brazilian grasslands. Nat. Conserv. 13, 95-104. Doi: 10.1016/j.ncon.2015.08.002

3. Besel, P.J., McKay, N.D., 1992. A method for registration of 3-D shapes. IEEE T. Pattern Anal, 14, 239256. Doi: $10.1109 / 34.121791$

4. Calders, K., Newnham, G., Burt, A., Murphy, S., Raumonen, P., Herold, M., Culvenor, D., Avitabile, V., Disney, M., Armston, J., Kaasalainen, M., (2015). Nondestructive estimates of above-ground biomass using terrestrial laser scanning. Methods Ecol. Evol. 6, 198-208. Doi: 10.1111/2041-210X.12301

5. Chen, J.J., Yi, S.H., Qin, Y., 2017. The contribution of plateau pika disturbance and erosion on patchy alpine grassland soil on the Qinghai-Tibetan Plateau: implications for grassland restoration. Geoderma. 297, 1-9. Doi: 10.1016/j.geoderma.2017.03.001

6. Damian, S.B., Hensgen, F., Wachendorf, M., Astor, T., 2019. Methods for LiDAR-based estimation of extensive grassland biomass. Comput. Electron. Agr, 156,693-699. DOI:

10.1016/j.compag.2018.11.041

7. Dong, S.K., Shang, Z.H., Gao, J.X., Boone, R.B., 2020. Enhancing sustainability of grassland ecosystems through ecological restoration and grazing management in an era of climate change on Qinghai-Tibetan Plateau. Agr. Ecosyst. Environ. 287. Doi: 10.1016/j.agee.2019.106684 
8. Eldridge, D.J., Bowker, M.A., Maestre, F.T., Roger, E., Reynolds, J.F., Whitford, W.G., 2011. Impacts of shrub encroachment on ecosystem structure and functioning: towards a global synthesis. Ecology letters. 14(7),709-722. Doi: 10.1111/j.1461-0248.2011.01630.x

9. Guo, Q.H., Li, W.K., Yu, H., Alvarez, O., 2010. Effects of topographic variability and lidar sampling density on several DEM interpolation methods. Photogramm. Eng. Remote Sens. 76, 701-712. Doi: 10.14358/PERS.76.6.701

10. Hilker, T., Coops, N.C., Culvenor, D.S., Newham, G., Wulder, M.A., Bater, C.W., Siggins, A., 2012. A simple technique for co-registration of terrestrial LiDAR observations for forestry applications. RemoteSens. Lett. 3, 239-247. DOI: 10.1080/01431161.2011.565815

11. Hosoi, F., Omasa, K., 2006. Voxel-Based 3-D Modeling of Individual Trees for Estimating Leaf Area Density Using High-Resolution Portable Scanning Lidar. IEEE T. Geosci. Remote, 44(12), 36103618. Doi: $10.1109 /$ tgrs.2006.881743

12. Kankare, V., Liang, X.L., Vastaranta, M., Yu, X.W., Holopainen, M., Hyypp, J., 2015. Diameter distribution estimation with laser scanning based multisource single tree inventory. ISPRS J. Photogram. Rem. Sens. 108, 161-171. Doi: 10.1016/j.isprsjprs.2015.07.007

13. Li, H.D., Li, Y.K., Gao, Y.Y., Zou, C.X., Yan, S.G., Gao, J.X., 2016. Human impact on vegetation dynamics around Lhasa, southern Tibetan Plateau, China. Sustainability, 8(11), 1146. Doi: 10.3390/su8111146

14. Li, H.D., Gao, J.X., Hu, Q.W., Li, Y.K., Tian, J.R., Liao, C.R., Ma, W.B., Xu, Y.N., 2019. Assessing revegetation effectiveness on an extremely degraded grassland, southern Qinghai-Tibetan Plateau, using terrestrial LiDAR and field data. Agr. Ecosyst. Environ, 282, 13-22. Doi: 10.1016/j.agee.2019.05.013

15. Liang, X.L., Litkey, P., Hyyppa, J., Kaartinen, H., Vastaranta, M., Holopainen, M., 2012. Automatic stem mapping using single-scan terrestrial laser scanning. IEEE Trans. Geosci. Remote Sens. 50, 661670. Doi: $10.1109 /$ TGRS.2011.2161613

16. Liang, X.L., Hyyppä, J., 2013. Automatic stem mapping by merging several terrestrial laser scans at the feature and decision levels. Sensors. 13, 1614-1634. Doi: 10.3390/s130201614

17. Liang, X.L., Kankare, V., Hyyppä, J., Wang, Y., Kukko, A., Haggrén, H., Yu, X.W., Kaartinen, H., Jaakkola, A., Guan, F., Holopainen, M., Vastaranta, M., 2016. Terrestrial laser scanning in forest inventories. ISPRS J. Photogram. Rem. Sens, 115, 63-77. Doi: 10.1016/j.isprsjprs.2016.01.006

18. Liang, X.L., Hyyppä, J., Kaartinen, H., Lehtomaki, M., Pyorala, J., Pfeifer, N., Holopainen, M., Brolly, G., Francesco, P., Hackenberg, J., 2018. International benchmarking of terrestrial laser scanning approaches for forest inventories. ISPRS J. Photogram. Rem. Sens. 144, 137-179. Doi: 10.1016/j.isprsjprs.2018.06.021

19. Liao, C.R., Liu, B.C., Xu, Y.N, Li, Y.K., Li, H.D., 2019. Effect of topography and protecting barriers on revegetation of sandy land, Southern Tibetan Plateau. Sci. Rept, 9, 6501. Doi: 10.1038/s41598-01943034-8

20. Liao, C.R., Li, H.D., Lv, G.P., Tian, J.R., Xu, Y.N., 2020. Effects of ecological restoration on soil properties of the aeolian sandy land around Lhasa, southern Tibetan Plateau. Ecosphere. 11(1), 1- 
13. Doi: $10.1002 /$ ecs 2.3009

21. Ministry of Environmental Protection, P. R. China. 2014. Technical Guidelines for Biodiversity Monitoring- Terrestrial Vascular Plants (HJ 710.1-2014). 2-6. (in Chinese).

22. Psomas, A., Kneubühler, M., Huber, S., Itten, K., Zimmermann, N.E., 2011. Hyperspectral remote sensing for estimating aboveground biomass and for exploring species richness patterns of Grassland habitats. Int.J.RemoteSens. 32, 9007-9031. Doi: 10.1080/01431161.2010.532172

23. Pueschel, P., Newnham, G., Rock, G., Udelhoven, T., Werner, W., Hill, J., 2013. The influence of scan mode and circle fitting on tree stem detection, stem diameter and volume extraction from terrestrial laser scans. ISPRS J. Photogram. Rem. Sens. 77, 44-56. Doi: 10.1016/j.isprsjprs.2012.12.001

24. Scurlock, J.M.O., Hall, D.O., 1998. The global carbon sink: a grassland perspective. Glob. Change Biol. 4, 229-233. Doi: 10.1046/j.1365-2486.1998.00151.x

25. Saarinen, N., Kankare, V., Vastaranta, M., Luoma, V., Pyorälä, J., Tanhuanpää, T., Liang, X., Kaartinen, H., Kukko, A., Jaakkola, A., Yu, X., Holopainen, M., Hyyppä, J., 2017. Feasibility of Terrestrial laser scanning for collecting stem volume information from single trees. ISPRS J. Photogram. Rem. Sens. 123, 140-158. Doi: 10.1016/j.isprsjprs.2016.11.012

26. Tian, J.R., Dai, T.T., Li, H.D., Liao, C.R., Teng, W.X., Hu, Q.W., Ma, W.B., Xu, Y.N., 2019. A Novel Tree Height Extraction Approach for Individual Trees by Combining TLS and UAV Image-Based Point Cloud Integration. Forests, 10(7), 537. Doi: 10.3390/f10070537

27. Tian, J.R., Li, H.D., Li, Y. K., Liao, C.R., Ma, W.B., Xu, Y.N., 2020. Feasibility of Terrestrial Laser Scanning in Quantification of Vegetation Structure Parameters of Restored Sandy Land in Southern QinghaiTibet Plateau. Land Degrad. Dev. Doi:10.1002/Idr.3784

28. Trochta, J., Kral, K., Janik, D., Adam, D., 2013. Arrangement of terrestrial laser scanner positions for area-wide stem mapping of natural forests. Can. J. For. Res. 43, 355-363. 13. DOI: 10.1139/cjfr2012-0347

29. Wachendorf, M., Fricke, T., Möckel, T., 2017. Remote sensing as a tool to assess botanical composition, structure, quantity and quality of temperate grasslands. Grass Forage Sci. 1-14. doi.org/10.1111/gfs. 12312

30. Wan, P., Wang, T.J., Zhang, W.M., Liang, X.L., Skidmore, A.K., Yan, G.J., 2019. Quantification of occlusions influencing the tree stem curve retrieving from single-scan terrestrial laser scanning data. For Ecosyst, 6,1. DOI: 10.1186/s40663-019-0203-1

31. Xu, K.X., Su, Y.J., Liu, J., Hu, T.Y., Jin, S.C., Ma, Q., Zhai, Q.P., Wang, R., Zhang, J., Li, Y.M., Liu, H.Y., Guo, Q.H., 2020. Estimation of degraded grassland aboveground biomass using machine learning methods from terrestrial laser scanning data. Ecol Indic. 108. Doi: 10.1016/j.ecolind.2019.105747

32. Zhao, X.Q., Guo, Q.H., Su, Y.J., Xue, B.L., 2016. Improved progressive TIN densification filtering algorithm for airborne LiDAR data in forested areas. ISPRS J. Photogramm. Rem. Sens, 117, 7991. Doi: 10.1016/j.isprsjprs.2016.03.016

\section{Figures}



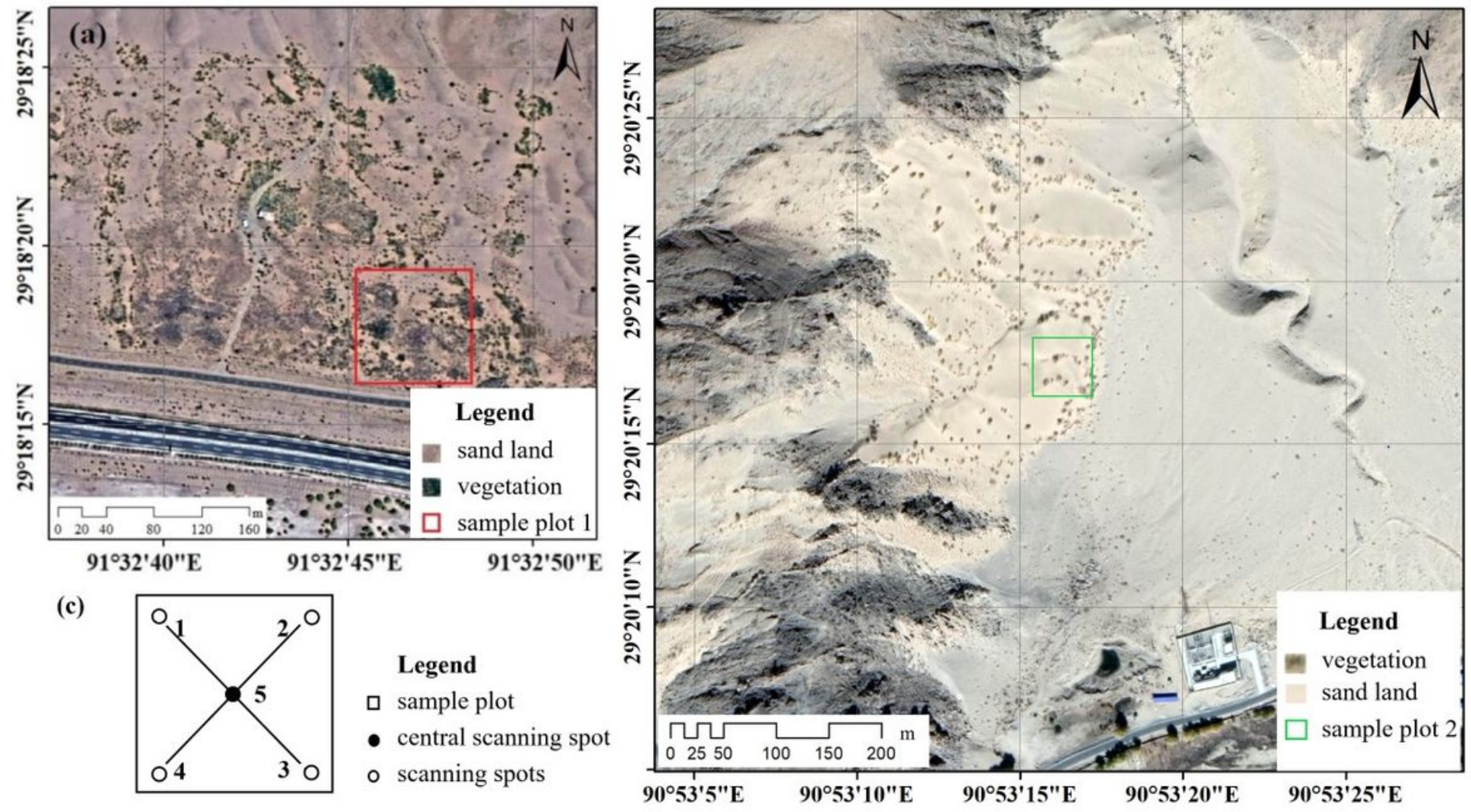

Figure 1

(a) the map of the sample plot 1, (b) the map of the sample plot 2, (3) the setting schematic of TLS scanning spots (scanning spot 5 is the central scanning spot). Note: The designations employed and the presentation of the material on this map do not imply the expression of any opinion whatsoever on the part of Research Square concerning the legal status of any country, territory, city or area or of its authorities, or concerning the delimitation of its frontiers or boundaries. This map has been provided by the authors. 


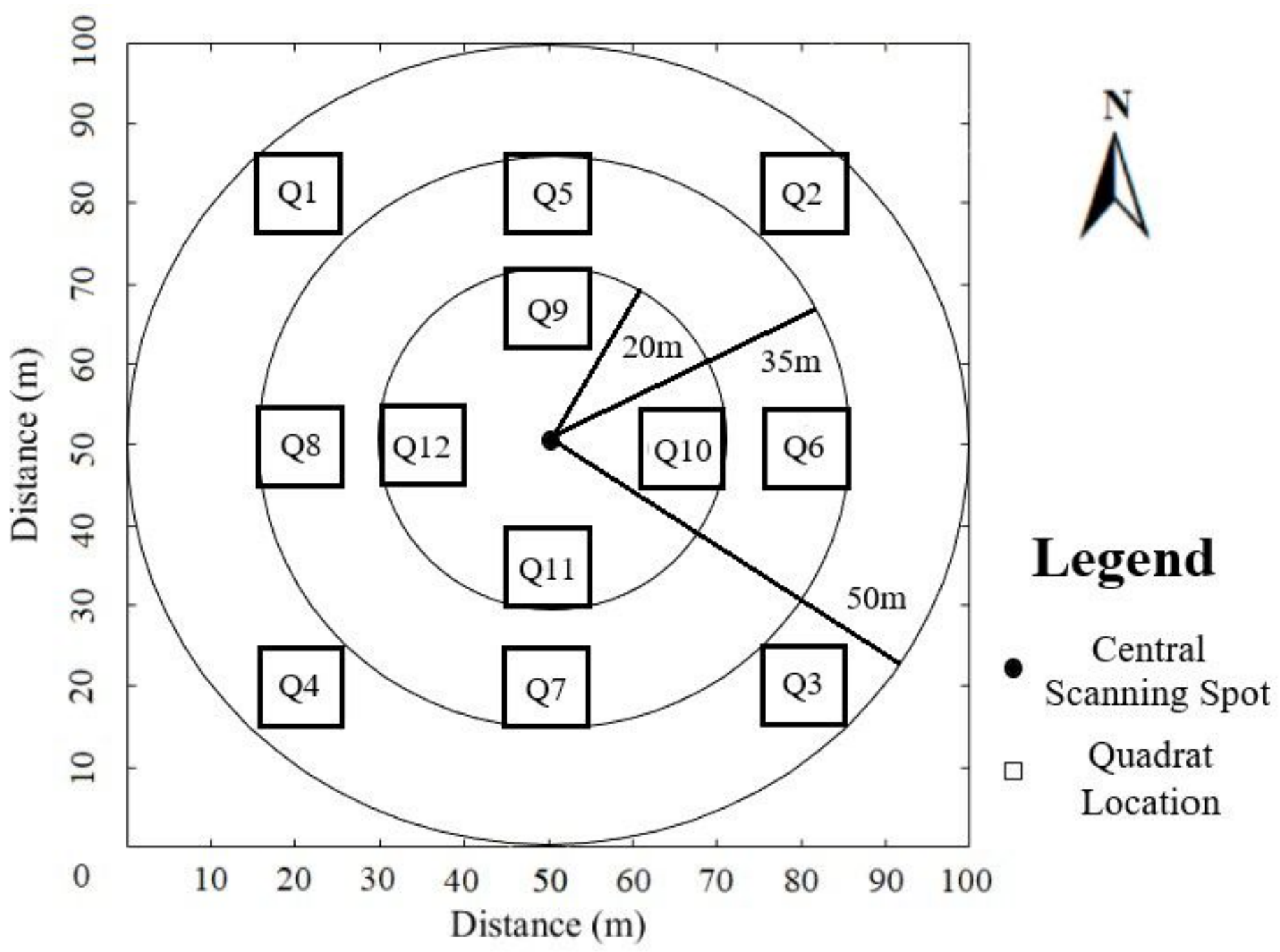

Figure 2

The distribution of quadrats in the sample plot 1 .

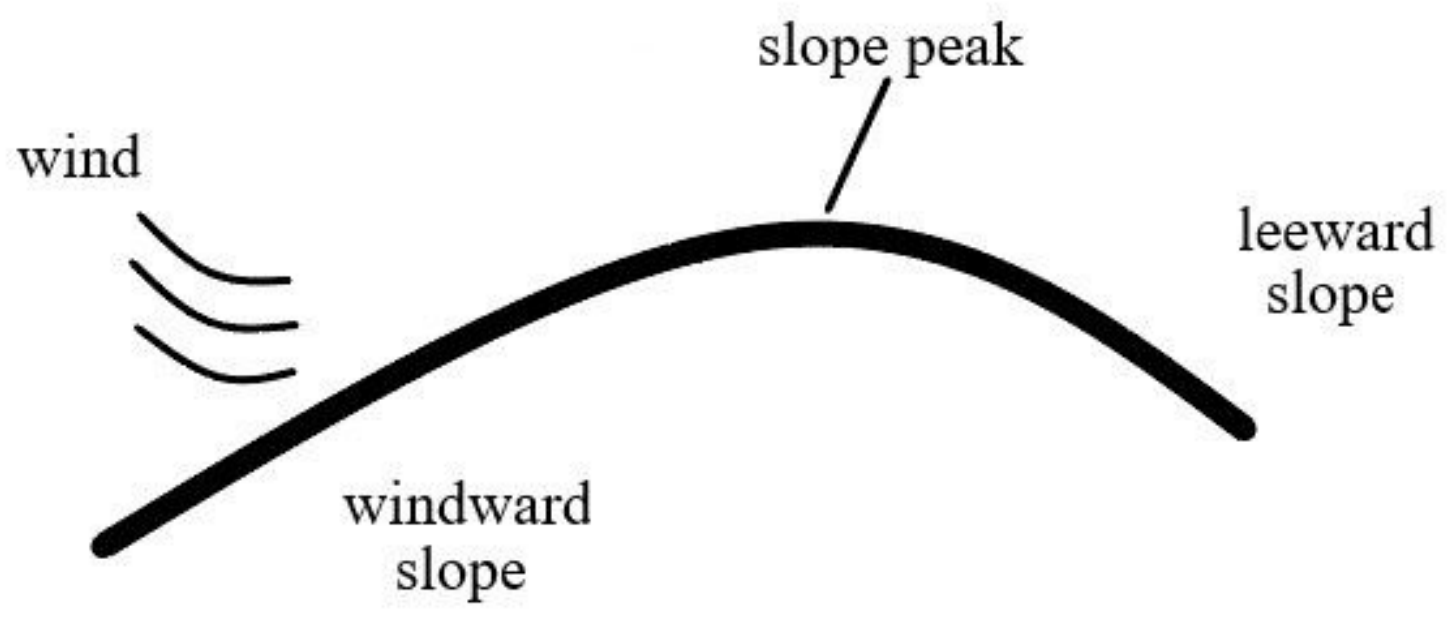

Figure 3 
the diagrammatic drawing of the slope peak

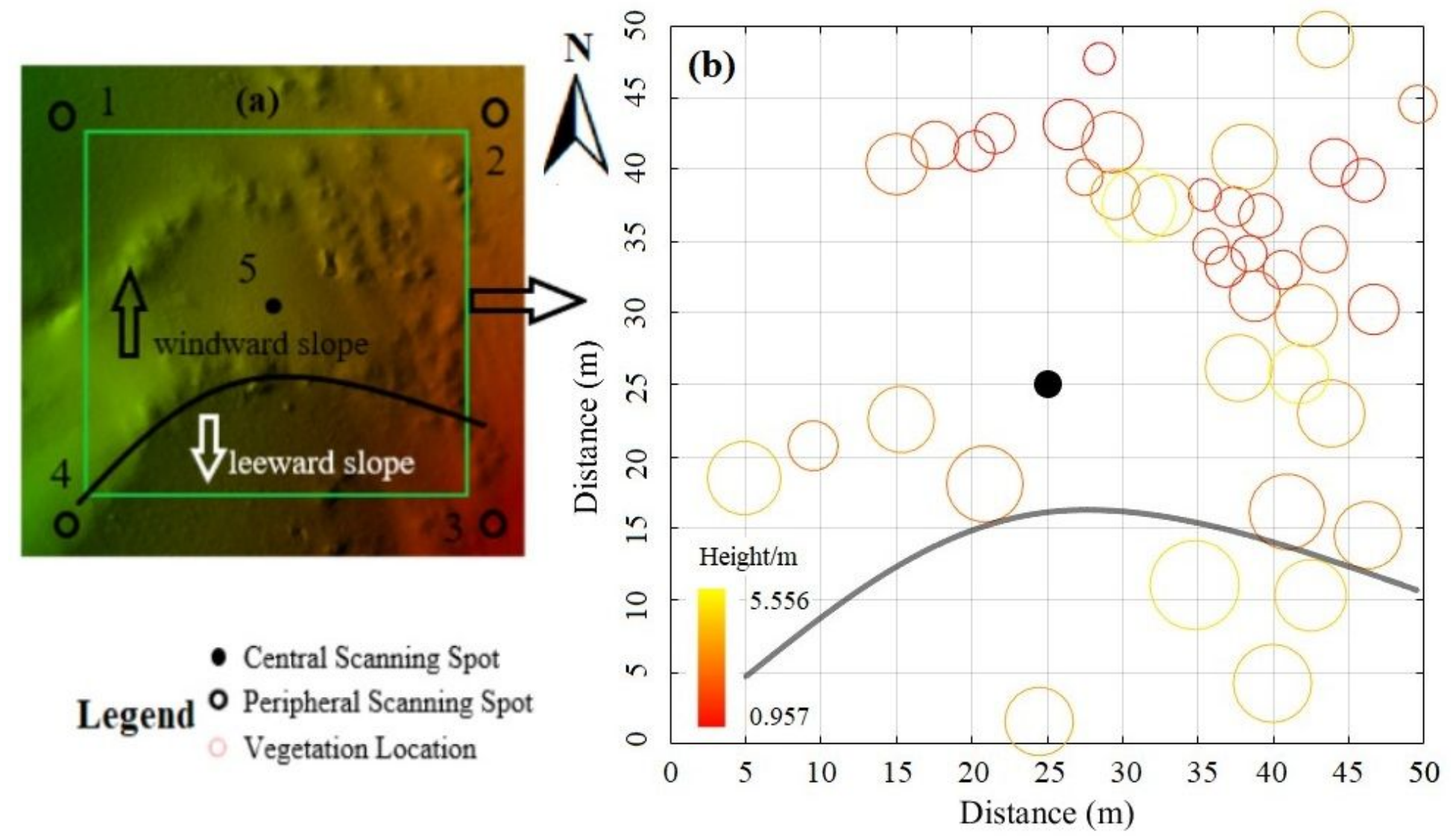

Figure 4

(a) the terrain diagram of sample plot 2, (b) the distribution of vegetation in sample plot 2, the size of the circle represents the crown width of vegetation, and the color represents the height of vegetation. 

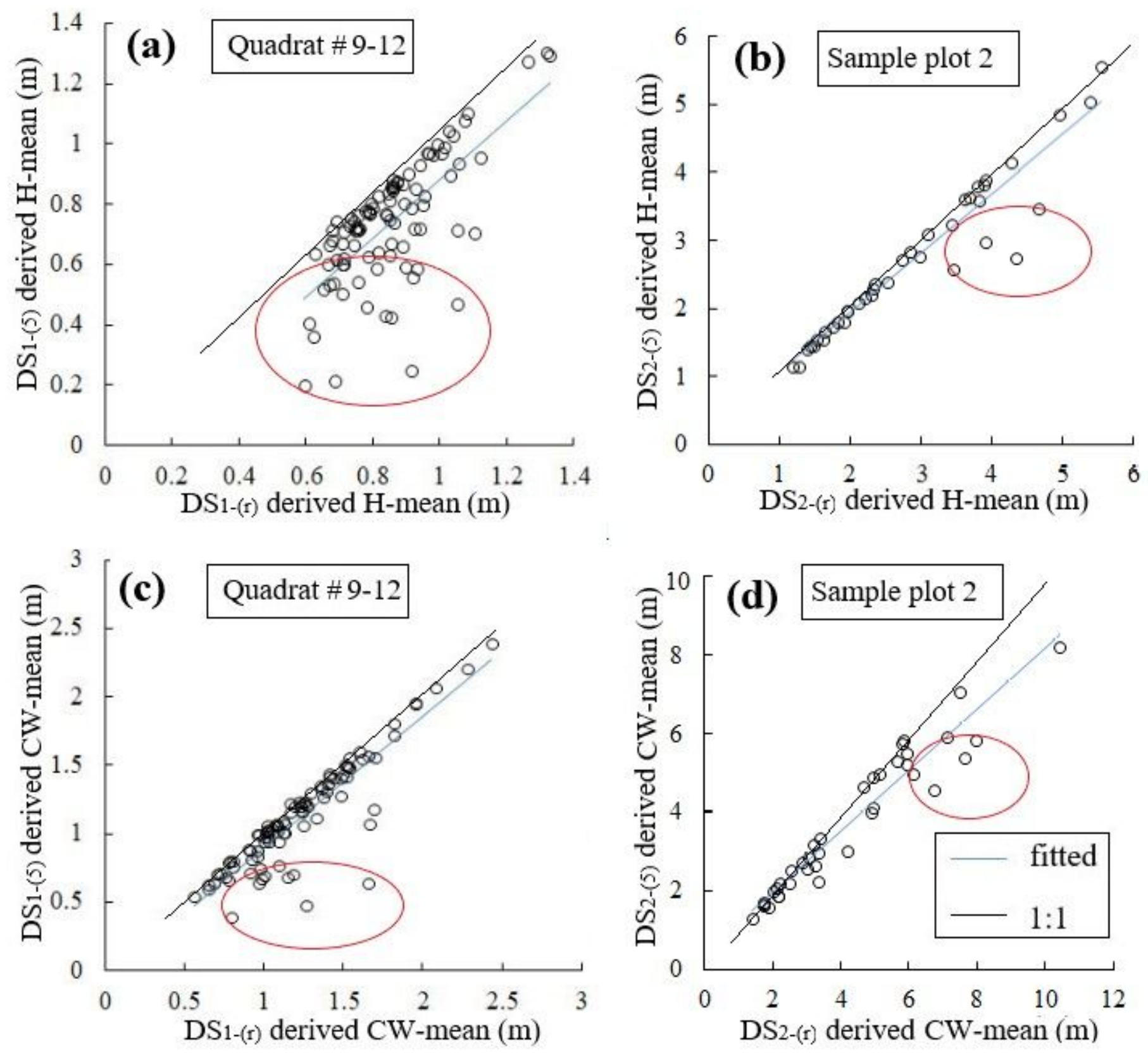

Figure 5

Scatter plots between SS-derived (DS1-(5) \& DS2-(5)) and MS-derived (DS1-(r) \& DS2-(r)) (a) H-mean in quadrats \#9-12, (b) H-mean in sample plot 2, (c) CW-mean in quadrats \#9-12, and (d) CW-mean in sample plot 2. The error of the point at the red circle is large, the blue line represents the fitted line, and the black line represents the 1:1 line. 